Supporting Information

\title{
Blow-Spinning Enabled Precise Doping and Coating for Improving High Voltage Lithium Cobalt Oxide Cathode Performance
}

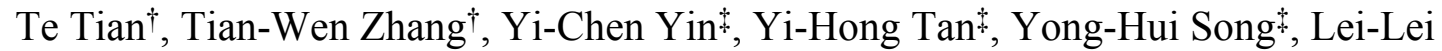
$\mathrm{Lu}^{\dagger}$, Hong-Bin $\mathrm{Yao}^{\dagger, \ddagger}, *$

Division of Nanomaterials \& Chemistry, Hefei National Laboratory for Physical Sciences at the Microscale, University of Science and Technology of China, Hefei, Anhui 230026, China.

Department of Chemistry, Department of Applied Chemistry, University of Science and Technology of China, Hefei, Anhui 230026, China.

*Corresponding author. yhb@ustc.edu.cn 


\section{Experimental Section}

Materials and Chemicals. Lithium acetate dihydrate $\left(\mathrm{C}_{2} \mathrm{H}_{3} \mathrm{O}_{2} \mathrm{Li} \cdot 2 \mathrm{H}_{2} \mathrm{O}\right.$, Sinopharm Chemical Reagent Co. Ltd. (SCRC), Analytical Reagent (AR)), Cobaltous acetate tetrahydrate $\left(\mathrm{C}_{4} \mathrm{H}_{6} \mathrm{CoO}_{4} \cdot 4 \mathrm{H}_{2} \mathrm{O}, \quad \mathrm{SCRC}, \mathrm{AR}\right)$, Manganous acetate tetrahydrate $\left(\mathrm{C}_{4} \mathrm{H}_{6} \mathrm{MnO}_{4} \cdot 4 \mathrm{H}_{2} \mathrm{O}, \mathrm{SCRC}, \mathrm{AR}\right)$, Tetrabutyl titanate $\left(\mathrm{C}_{16} \mathrm{H}_{36} \mathrm{O}_{4} \mathrm{Ti}, \mathrm{SCRC}\right.$, Chemically Pure (CP)), Lanthanum(III) nitrate hexahydrate $\left(\mathrm{La}\left(\mathrm{NO}_{3}\right)_{3} \cdot 6 \mathrm{H}_{2} \mathrm{O}\right.$, Alfa Aesar, 99.9\%), Methanol $\left(\mathrm{CH}_{4} \mathrm{O}, \mathrm{SCRC}, \mathrm{AR}\right)$, Acetone $\left(\mathrm{C}_{3} \mathrm{H}_{6} \mathrm{O}, \mathrm{SCRC}, \mathrm{AR}\right)$, Lithium carbonate ( $\left.\mathrm{Li}_{2} \mathrm{CO}_{3}, \mathrm{SCRC}, \mathrm{AR}\right)$, Citric acid monohydrate $\left(\mathrm{C}_{6} \mathrm{H}_{8} \mathrm{O}_{7} \cdot \mathrm{H}_{2} \mathrm{O}, \mathrm{SCRC}\right.$, AR), Glacial acetic acid $\left(\mathrm{C}_{2} \mathrm{H}_{4} \mathrm{O}_{2}, \mathrm{SCRC}, \mathrm{AR}\right)$, Polyvinylpyrrolidone (PVP, $\mathrm{M}_{\mathrm{w}}=1300000$, SigmaAldrich)

Preparation of bare-LCO and co-modified-LCO. The precursor solution was prepared by mixing the desired amount of $\mathrm{C}_{2} \mathrm{H}_{3} \mathrm{O} 2 \mathrm{Li} \cdot 2 \mathrm{H}_{2} \mathrm{O}, \mathrm{C}_{4} \mathrm{H}_{6} \mathrm{CoO}_{4} \cdot 4 \mathrm{H}_{2} \mathrm{O}$, $\mathrm{C}_{4} \mathrm{H}_{6} \mathrm{MnO}_{4} \cdot 4 \mathrm{H}_{2} \mathrm{O}, \mathrm{C}_{16} \mathrm{H}_{36} \mathrm{O}_{4} \mathrm{Ti}, \mathrm{La}\left(\mathrm{NO}_{3}\right)_{3} \cdot 6 \mathrm{H}_{2} \mathrm{O}$ in the methanol and acetic acid mixed solvents with a volume ratio of $9: 1$. As a typical example, in the case of synthesizing $\mathrm{LiCo}_{0.944} \mathrm{Mn}_{0.05} \mathrm{La}_{0.001} \mathrm{Ti}_{0.005} \mathrm{O}_{2}$ (M5L0.1T0.5-LCO), 3.8556 g of $\mathrm{C}_{2} \mathrm{H}_{3} \mathrm{O}_{2} \mathrm{Li} \cdot 2 \mathrm{H}_{2} \mathrm{O}, 8.462$ g of $\mathrm{C}_{4} \mathrm{H}_{6} \mathrm{CoO}_{4} \cdot 4 \mathrm{H}_{2} \mathrm{O}, 0.441 \mathrm{~g}$ of $\mathrm{C}_{4} \mathrm{H}_{6} \mathrm{MnO}_{4} \cdot 4 \mathrm{H}_{2} \mathrm{O}, 0.062 \mathrm{~g}$ of $\mathrm{C}_{16} \mathrm{H}_{36} \mathrm{O}_{4} \mathrm{Ti}$, and 0.0156 $\mathrm{g}$ of $\mathrm{La}\left(\mathrm{NO}_{3}\right)_{3} \cdot 6 \mathrm{H}_{2} \mathrm{O}$ were dissolved completely in the $45 \mathrm{~mL}$ of methanol and $5 \mathrm{~mL}$ of acetic acid mixed solvents after stirring for $30 \mathrm{~min}$. Then, $0.71 \mathrm{~g}$ of PVP ( $2 \mathrm{wt}$. \%) was added into the above solution, and the resultant solution was magnetically stirred for $\sim 3$ hours at the room temperature. The mixture was loaded into a $50 \mathrm{~mL}$ syringe with a specific coaxial needle (inner diameters: $0.16 \mathrm{~mm}$ ). The precursor solution with $2 \mathrm{wt} . \%$ of PVP was injected from the needle under a gas pressure of $100 \mathrm{Kpa}$ from the outer 
shaft with a speed of $10 \mathrm{~mL}_{\text {hour }}^{-1}$ toward a porous and air-permeable cage collector placed at a distance of $25 \mathrm{~cm}$. The cage-like collector we used is homemade. We bend the purchased iron wire mesh into a cylinder, and then add an iron wire mesh cover at the bottom. The diameter of the cylinder is $20 \mathrm{~cm}$, and the length of the cylinder is 45 $\mathrm{cm}$. The aperture of the iron wire mesh is $1.6 \mathrm{~mm}$. After blow-spinning for 5 hours at the room temperature, a bunch of purple fibers was obtained in the cage. The precursor fibers were immediately collected and annealed at $900{ }^{\circ} \mathrm{C}$ for 6 hours in air with a heating rate of $2{ }^{\circ} \mathrm{C} \min ^{-1}$ to yield the final product. The yield of the finally obtained LCO particles from the precursor is $24.13 \%$.

\section{Preparation of single La-doped LCO via sol-gel method and solid-state reaction}

method. The solid-state method prepared La-doped LCO was carried out according to a literature ${ }^{[28]}$. Typically, in the case of synthesizing $\mathrm{LiCo}_{0.999} \mathrm{La}_{0.001} \mathrm{O}_{2}, 4.064 \mathrm{~g}$ of $\mathrm{Li}_{2} \mathrm{CO}_{3}\left(10 \% \mathrm{Li}\right.$ excess), $12.442 \mathrm{~g}$ of $\mathrm{C}_{4} \mathrm{H}_{6} \mathrm{CoO}_{4} \cdot 4 \mathrm{H}_{2} \mathrm{O}$ and $0.02165 \mathrm{~g}$ of $\mathrm{La}\left(\mathrm{NO}_{3}\right)_{3} \cdot 6 \mathrm{H}_{2} \mathrm{O}$ were mixed in an agate mortar using acetone to form a paste. After dried and annealed at $200{ }^{\circ} \mathrm{C}$, the sample was re-crushed and subsequently annealed at $900^{\circ} \mathrm{C}$ for 20 hours. For the sol-gel method ${ }^{[10]}, 5.6109 \mathrm{~g}$ of $\mathrm{C}_{2} \mathrm{H}_{3} \mathrm{O}_{2} \mathrm{Li} \cdot 2 \mathrm{H}_{2} \mathrm{O}$ (10\% Li excess), $12.4420 \mathrm{~g}$ $\mathrm{C}_{4} \mathrm{H}_{6} \mathrm{CoO}_{4} \cdot 4 \mathrm{H}_{2} \mathrm{O}$ and $0.02165 \mathrm{~g} \mathrm{La}\left(\mathrm{NO}_{3}\right)_{3} \cdot 6 \mathrm{H}_{2} \mathrm{O}$ were dissolved in distilled water and citric acid was used as the chelating agent. The mixed sol was heated at $80^{\circ} \mathrm{C}$ and stirred for 3-4 hours to evaporate the solvent and get the gel precursor. After dried at $120{ }^{\circ} \mathrm{C}$, the gel powder was annealed at $900{ }^{\circ} \mathrm{C}$ for 6 hours to obtain the final product.

Electrode preparation and cell assembly. The LCO cathodes were fabricated by blending 90 wt.\% active material, 5 wt.\% poly(vinylidene difluoride) (PVDF) as the 
binder and 5 wt.\% carbon black as the conductive additive in N-methyl-2-pyrrolidone (NMP) to form a slurry. The slurry was subsequently casted onto the aluminum foil and dried at $110^{\circ} \mathrm{C}$ in a vacuum oven overnight. The mass loadings of cathode materials in all cells were kept at $\sim 12 \mathrm{mg} \mathrm{cm}^{-2}$. Coin cells (2032-type) were assembled using the asprepared electrodes as the cathodes, lithium metal foils as the anodes and polypropylene (PP, Celgard 2400) as the separators. $0.6 \mathrm{M} \mathrm{LiPF}_{6}$ and $0.4 \mathrm{M}$ Lithium oxalyldifluroborate (LiODFB) in ethylene carbonate/dimethyl carbonate/ethyl methyl carbonate mixture (1:1:1 in volume ratio) was used as the electrolyte.

Electrochemical measurements. The galvanostatic charge-discharge cycling test was carried out in the voltage rang from 3.0 to $4.5 \mathrm{~V}\left(\mathrm{vs}\right.$. $\left.\mathrm{Li} / \mathrm{Li}^{+}\right)$for cycle stability evaluation and $3.0 \mathrm{~V}$ to $4.6 \mathrm{~V}\left(\mathrm{vs} . \mathrm{Li} / \mathrm{Li}^{+}\right)$for rate performance evaluation at room temperature by an eight-channel LAND battery tester. For the tests, the initial three activation cycles were processed under a constant current of $0.1 \mathrm{C}\left(1 \mathrm{C}=2.74 \mathrm{~mA} \mathrm{~cm}^{-2}\right)$. After that, the cells were operated under a rate of $0.3 \mathrm{C}$ and $1 \mathrm{C}$, respectively. The electrochemical impedance spectroscopy (EIS), galvanostatic intermittent titration technique (GITT) measurements were carried out on the electrochemical work station (Biologic VSP300). To determine the lithium ion diffusion coefficients for bare $\mathrm{LiCoO}_{2}$ and modified $\mathrm{LiCoO}_{2}$, the GITT measurements were conducted as the followings: a $10 \mathrm{~min}$ galvanostatic charge pulse $(0.1 \mathrm{C})$ was applied to the cell, followed by 2 hours of relaxation time without any current being passed through the cell. The cycle, consisting of a charge pulse and a relaxation period, was applied to the cell until its voltage increased to $4.5 \mathrm{~V}$ versus $\mathrm{Li} / \mathrm{Li}^{+}$. Then, a discharge pulse $(0.1 \mathrm{C}, 10 \mathrm{~min})$ was applied to 
the cell, followed by a 2 hours relaxation period without any current flowing through the cell. The cycle was applied to the cell until its voltage reached to $3.0 \mathrm{~V}$ versus $\mathrm{Li} / \mathrm{Li}^{+}$. Two charging-discharging cycles from $3.0 \mathrm{~V}$ to $4.5 \mathrm{~V}$ versus $\mathrm{Li} / \mathrm{Li}^{+}$for GITT measurement were carried out on all electrodes. The lithium ion diffusion coefficients of the bare LCO and modified LCO were calculated by the following equation:

$$
\mathrm{D}=\frac{4 r^{2}}{\pi \tau}\left(\Delta E_{s} / \Delta E_{t}\right)^{2}
$$

where $\tau$ is the pulse time, $r$ is the average particle radius of the cathode material (The average diameter of the obtained LCO particles was $0.36 \mu \mathrm{m}), \Delta E_{s}$ and $\Delta E_{t}$ is the change of the steady-state voltage of the cell for the above process and the total transient voltage change of the cell under the applied current during the pulse time, respectively. Characterizations. The microscale morphologies of precursor fibers and all prepared cathode materials were examined by scanning electron microscopy (SEM, JEOL-JSM6700F). The distribution of the elements in the precursor fibers was characterized by HITACHI UHR FE-SEM 30 (SU8200 Series) with an accelerating voltage of $20 \mathrm{KV}$ for EDX31 mapping. The high-resolution TEM (HRTEM) images, high-angle annulardark-field scanning transmission electron microscope (HAADF-STEM) images and the energy dispersive X-ray spectroscopy (EDS) elemental mapping were acquired on a Talos F200X transmission electron microscope at an accelerating voltage of $200 \mathrm{KV}$ equipped with an energy dispersive detector. The powder X-ray diffraction patterns were recorded using a Philips X'Pert PRO SUPER X-ray diffractometer equipped with graphite monochromatized $\mathrm{Cu} \mathrm{K} \alpha$ radiation. To confirm the elemental ratio of different 
dopants in the final products, all the elemental ratios were determined by a PerkinElmer Optima 7300 DV inductively coupled plasma-optical emission spectrometer (ICPOES). For the ICP-OES analysis, the samples were dissolved in $1 \% \mathrm{HNO}_{3}$ and $1 \% \mathrm{HCl}$ aqueous solutions. The resulting solution was filtered through a syringe filter with 0.22 $\mu \mathrm{m}$ average pore size to remove non-soluble components before the ICP analysis.

a

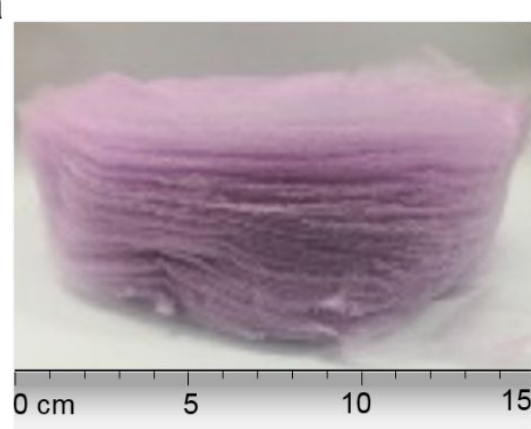

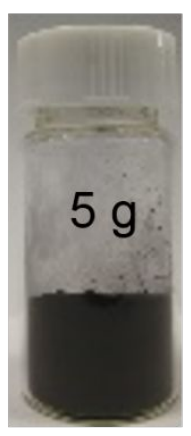

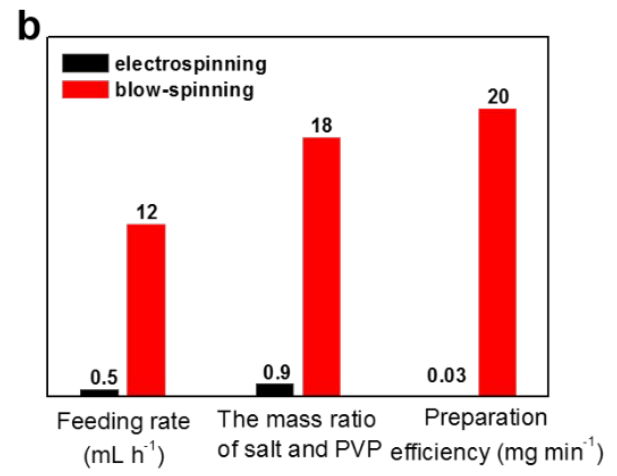

Figure S1. (a) Photograph of the as-spun precursor microfibers and the final LCO product. (b) Comparison of the material preparation efficiency between electrospinning and blow-spinning technique. 


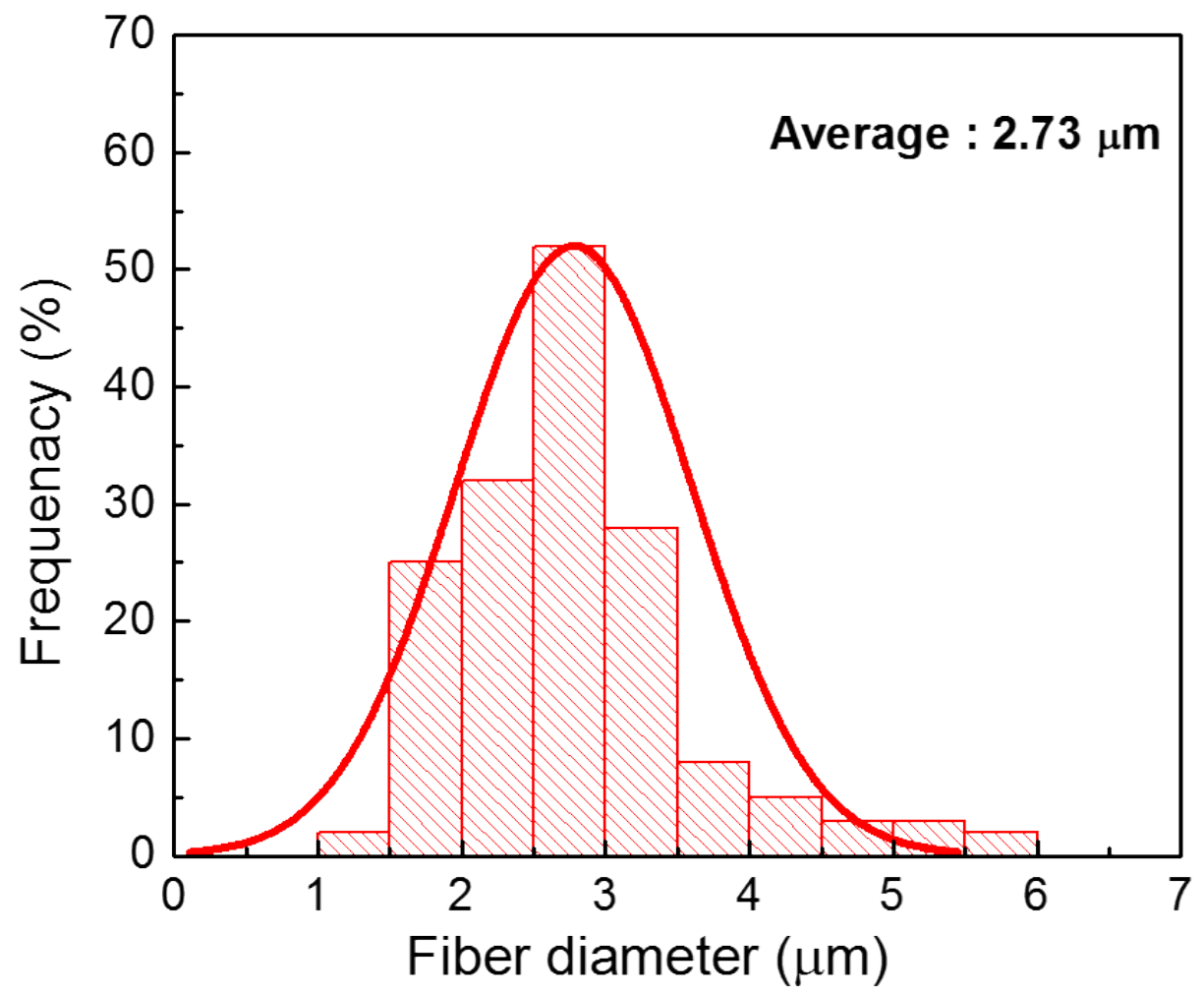

Figure S2. Diameter distribution of the as-spun microfibers. 
a

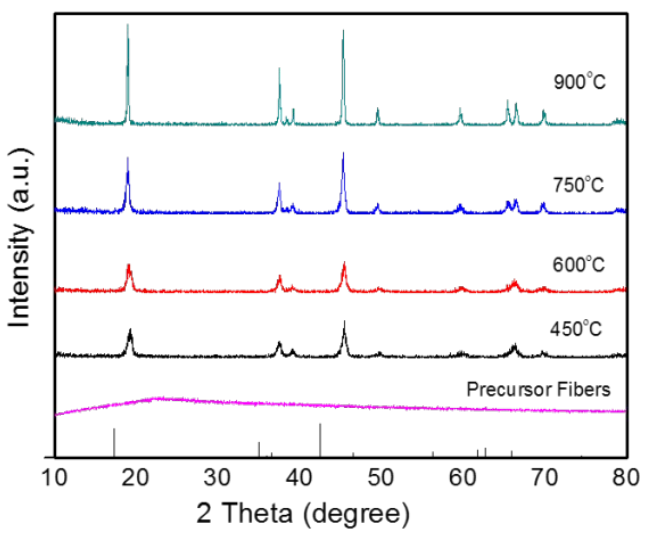

C

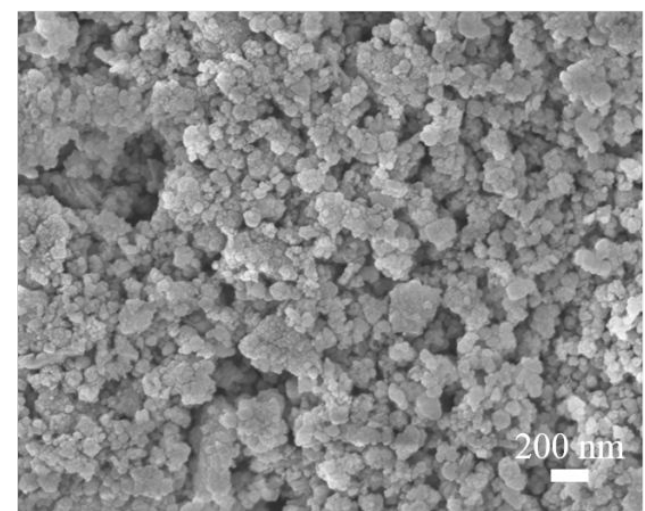

b

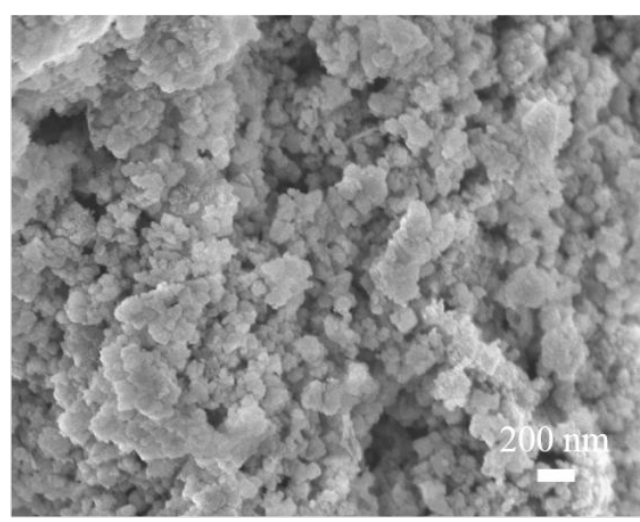

d

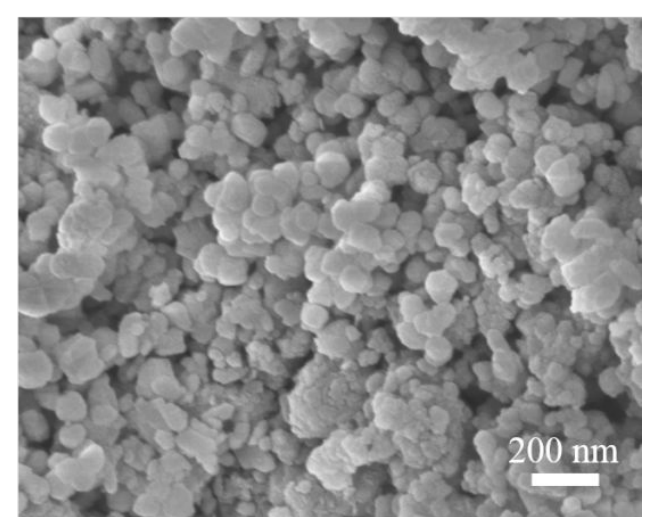

Figure S3. Characterization of the obtained M5L0.1T0.5-LCO particles at different annealing temperature. (a) PXRD patterns of the precursor fibers and M5L0.1T0.5-LCO particles annealing at $450{ }^{\circ} \mathrm{C}, 600{ }^{\circ} \mathrm{C}, 750{ }^{\circ} \mathrm{C}$ and $900{ }^{\circ} \mathrm{C}$. SEM image of M5L0.1T0.5-LCO particles annealing at (b) $450{ }^{\circ} \mathrm{C}$, (c) $600{ }^{\circ} \mathrm{C}$, and (d) $750^{\circ} \mathrm{C}$, respectively. 


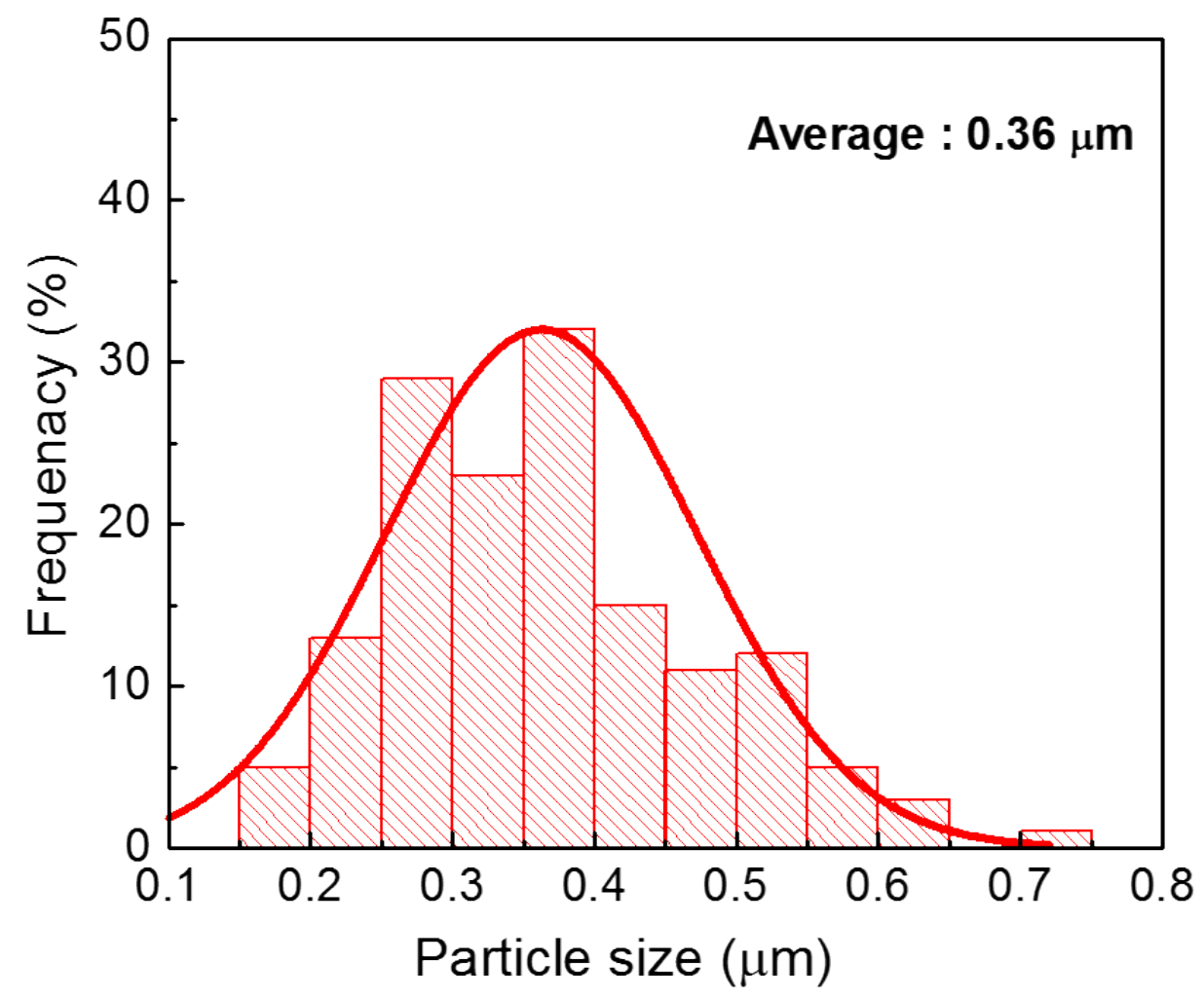

Figure S4. Diameter distribution of the M5L0.1T0.5-LCO particles. 
a

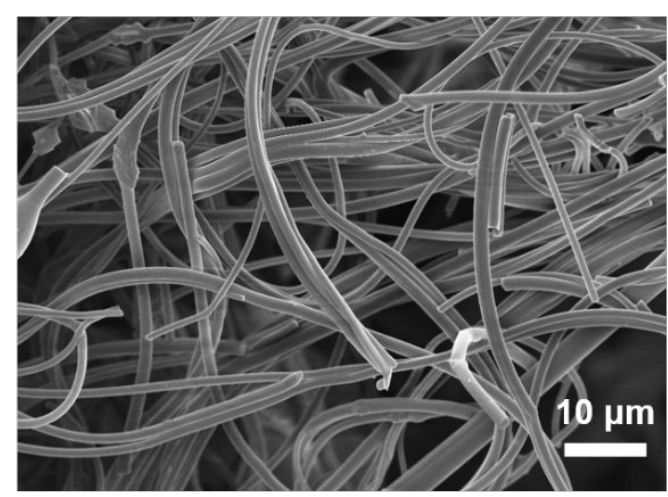

C

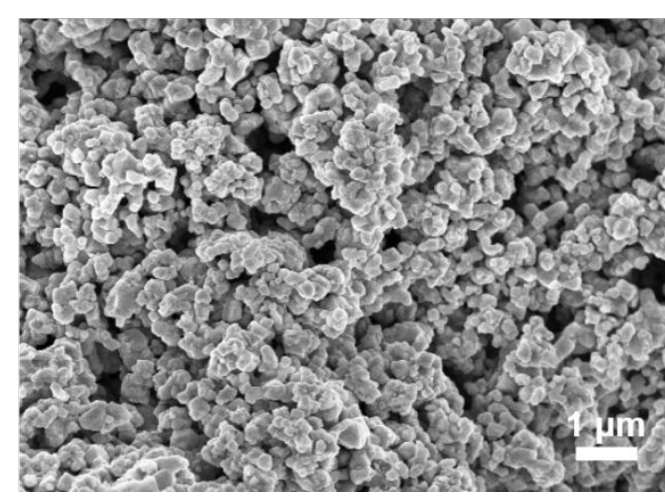

b

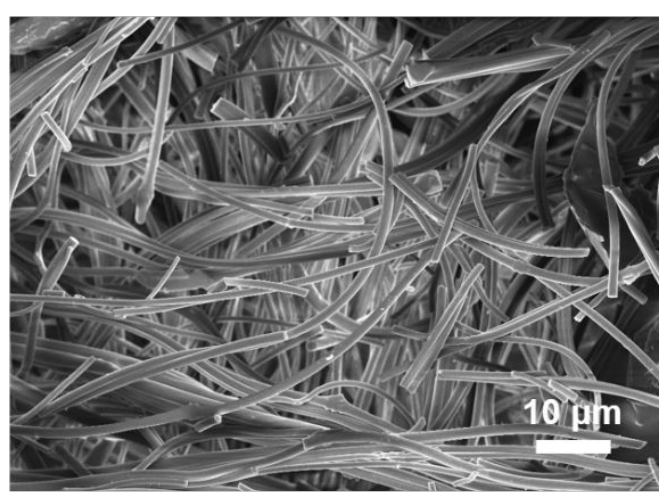

d

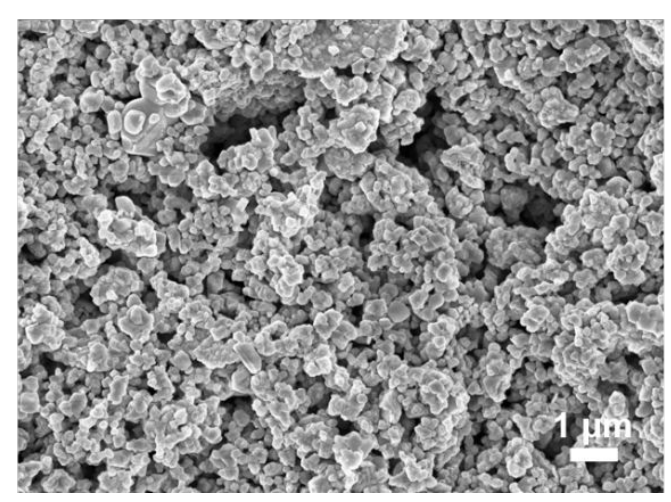

Figure S5. SEM image of the precursor fibers prepared by different size of inner nozzles: a) 0.26 $\mathrm{mm}$ and b) $0.41 \mathrm{~mm}$. SEM image of the finally obtained LCO particles with using different size of inner nozzles: c) $0.26 \mathrm{~mm}$ and d) $0.41 \mathrm{~mm}$. 


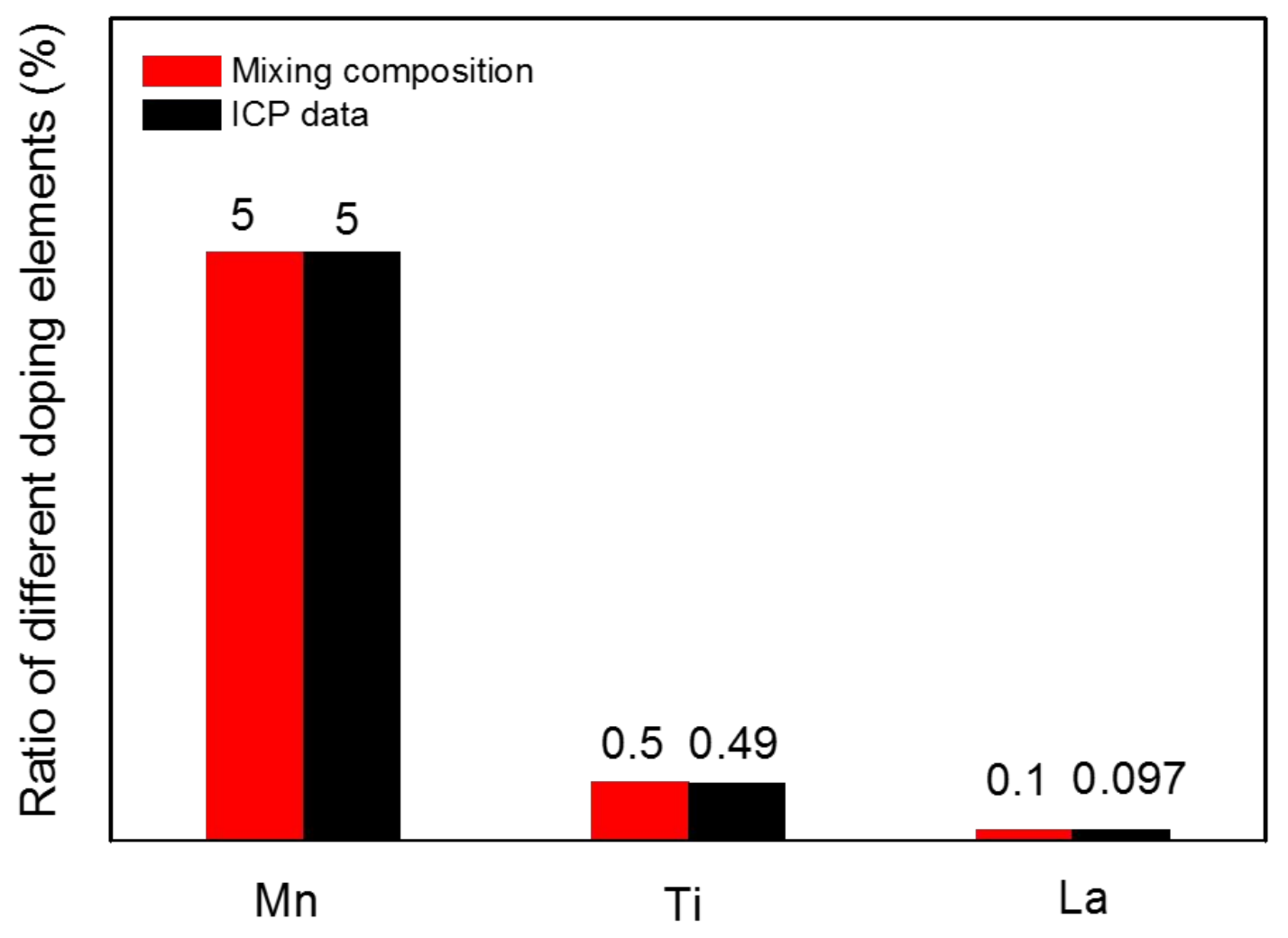

Figure S6. The comparison of ICP data and the precursor composition of the doping elements of $\mathrm{Mn}, \mathrm{La}$, Ti in the obtained LCO cathode. 

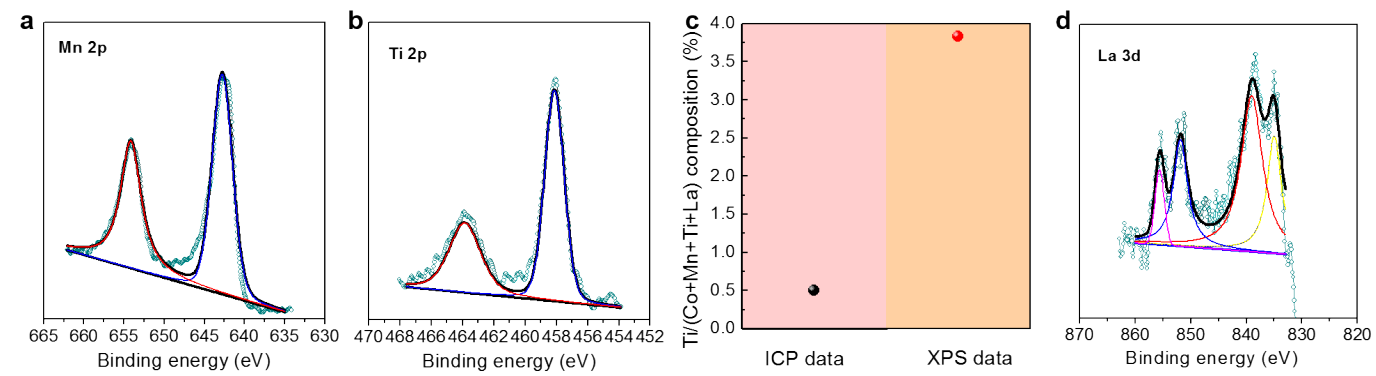

Figure S7. High-resolution XPS spectra of the M5L0.1T0.5-LCO. (a) Mn $2 p$ spectra, (b) Ti $2 p$ spectra. (c) The Ti-ratio comparison revealed by XPS and ICP analysis indicating the enrichment of Ti on the surface of the obtained LCO particles. (d) High-resolution La $3 d$ XPS spectra of the M5L0.1T0.5-LCO. 

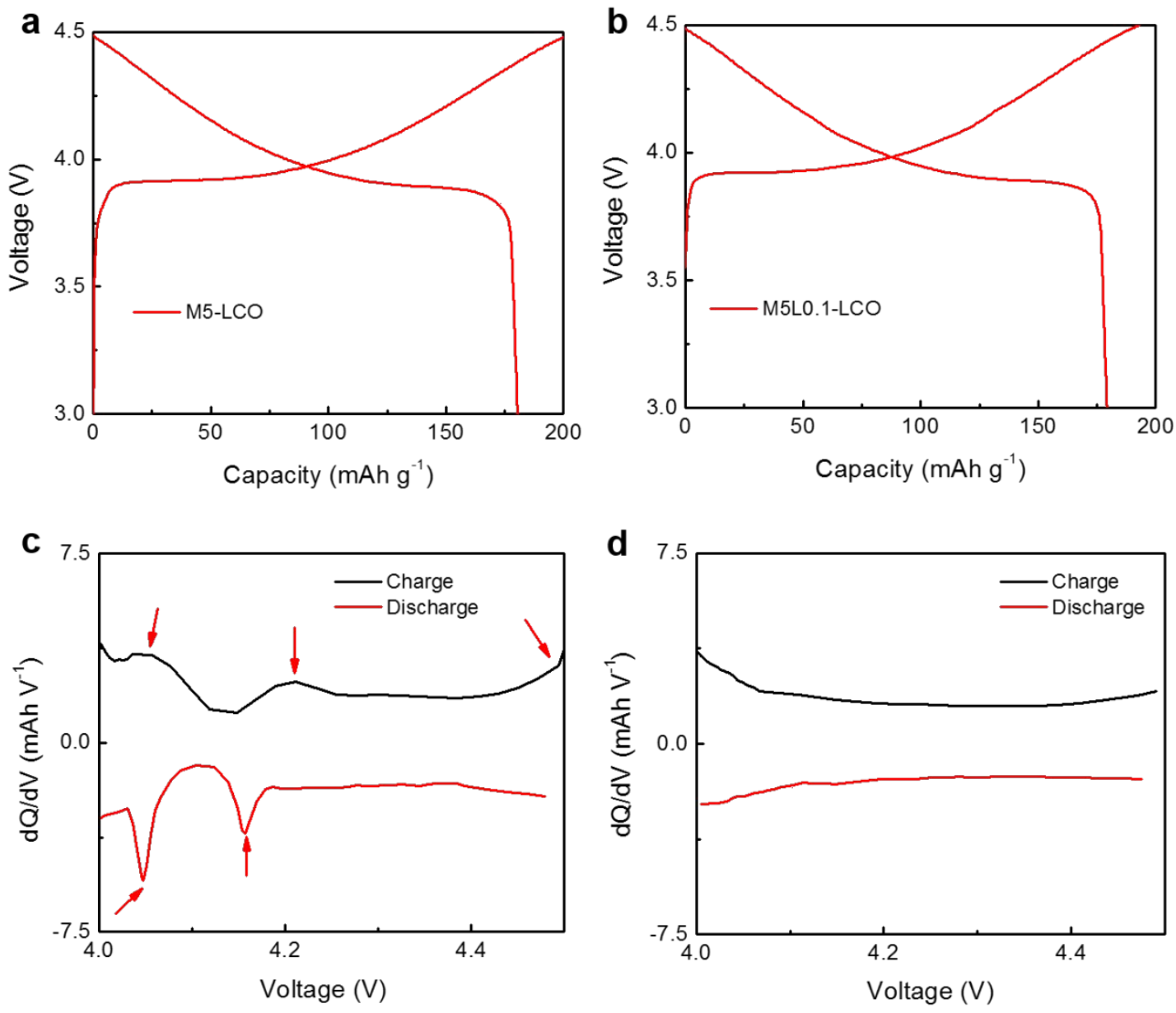

Figure S8. Electrochemical analysis of the mechanism of $\mathrm{Mn}^{4+}$ doping. (a) Charge-discharge voltage profile of the M5-LCO at 0.1C. (b) Charge-discharge voltage profile of the M5L0.1-LCO at $0.1 \mathrm{C}$. (c) The $\mathrm{dQ} / \mathrm{dV}$ curve of bare LCO during the initial activation cycle (the arrows in the profile indicate three distinct transitions respectively). (d) The dQ/dV curve of M5-LCO during the initial activation cycle. 

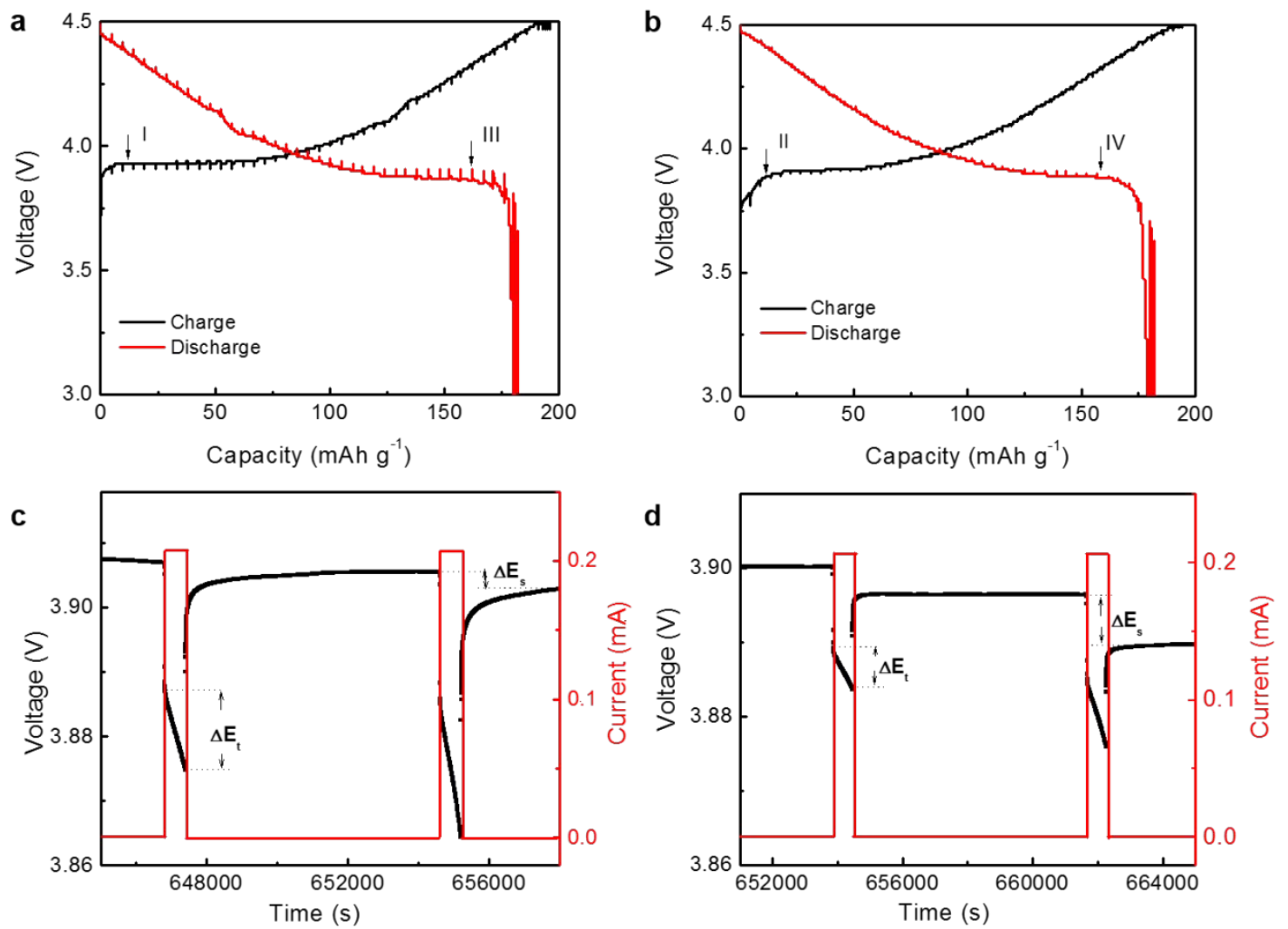

Figure S9. (a) The GITT curve of the bare LCO. (b) The GITT curve of the M5L0.1T0.5-LCO. (c) The GITT curve of bare LCO at the final discharging time marked as "III" in (a). (d) The GITT curve of M5L0.1T0.5-LCO at the final discharging time marked as "IV" in (b). 

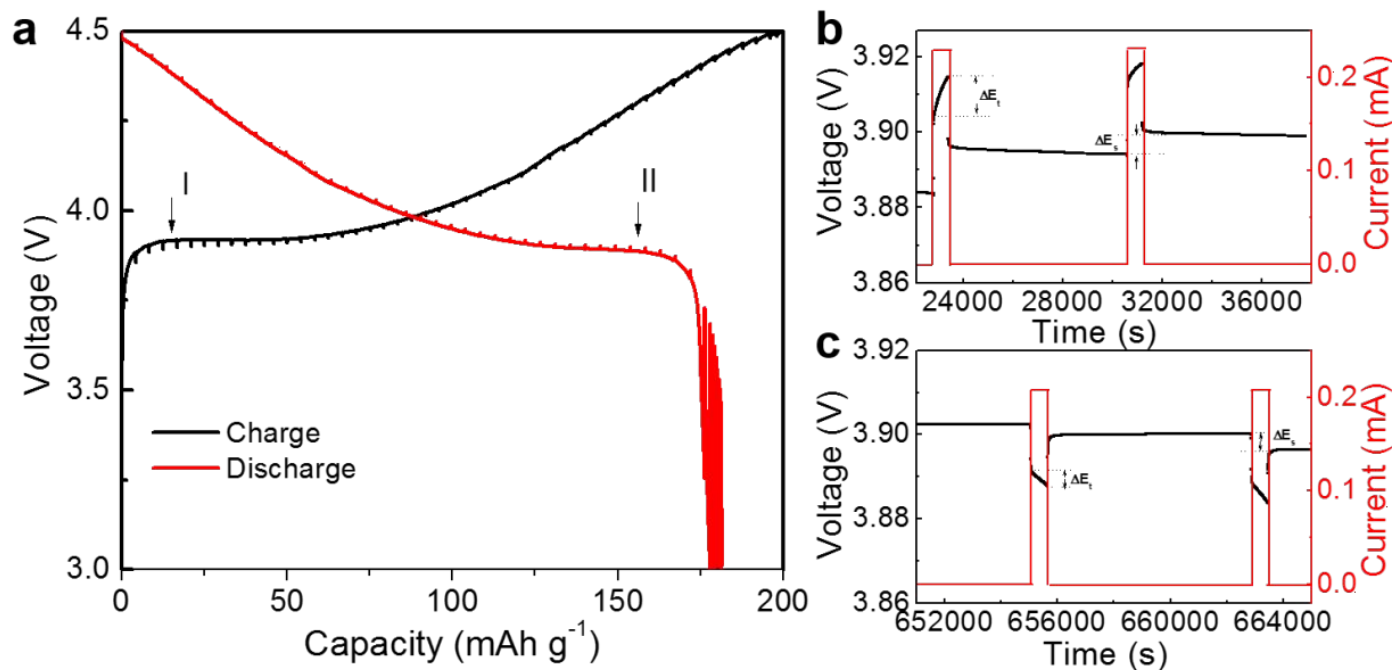

Figure S10. (a) The GITT curve of single La-doped LCO. (b) The GITT curve of single La-doped LCO at the initial charging time marked as "I" in (a). (c) The GITT curve of single La-doped LCO at the final discharging time marked as "II" in (a). The GITT test shows that the lithium ion diffusion coefficients for single La-doped LCO were determined to be $7.36 \times 10^{-12} \mathrm{~cm}^{2} / \mathrm{s}$ at the initial charging stage and $6.5 \times 10^{-12} \mathrm{~cm}^{2} / \mathrm{s}$ at the final discharging state. 


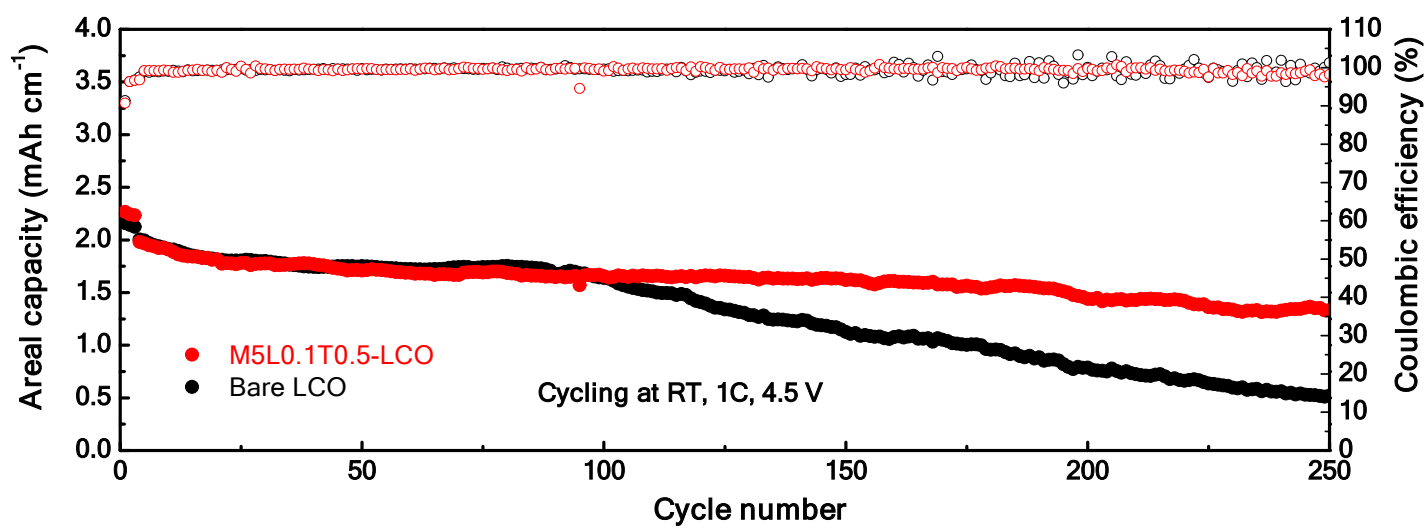

Figure S11. Long-term cycling performance of half-cells with bare LCO and M5L0.1T0.5 electrodes at room temperature in the voltage range of 3.0-4.5 V at $1 \mathrm{C}$. All cells were pre-cycled for three cycles at $0.1 \mathrm{C}$. 


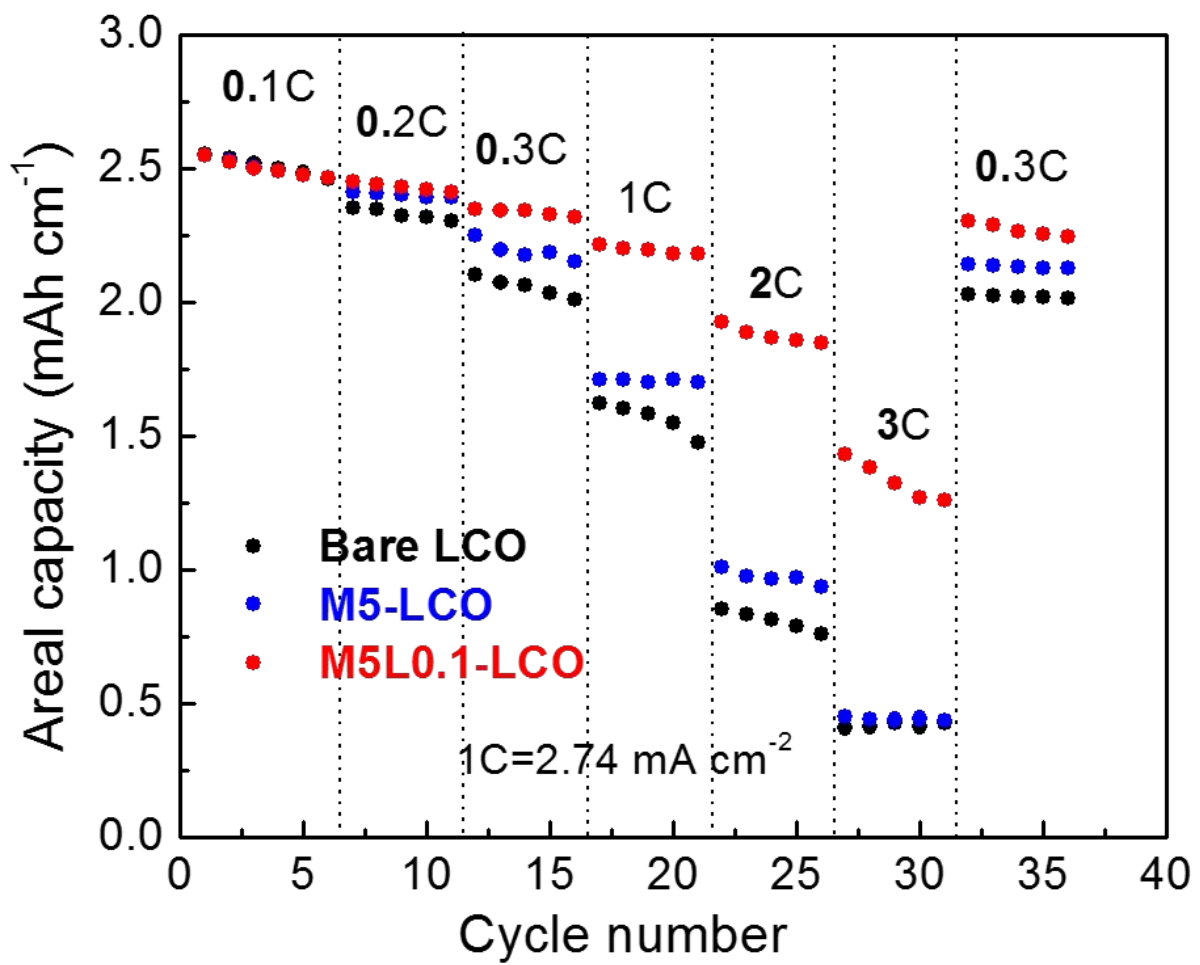

Figure S12. Rate performance of bare LCO, M5-LCO and M5L0.1-LCO electrodes at room temperature in the voltage range of 3.0-4.6 V. 
